\title{
Comparison of Success Rate of Vaginal Birth after Cesarean Between Women with Lower Segment Uterine Scar Thickness more than and less than $3.5 \mathrm{~mm}$
}

\author{
Robina Ali', Fatima Abid², Faiza Aslam³ ${ }^{3}$ Shumaila Batool ${ }^{4}$
}

\author{
1 Professor, Department of Gynecology, PMC/FMU Allied \& DHQ Hospitals, Faisalabad Pakistan \\ 1 Manuscript writing, Tabulation of results, Discussion writing, Proof reading \\ 2 House Officer, Allied/DHQ Hospital, Faisalabad Pakistan \\ 2 Results compiling \\ 3 Post Graduate Resident, Department of Gynecology \& Obstetrics Unit-II DHQ Hospital, Faisalabad Pakistan \\ 3 Data collection, Data analysis \\ 4 Post Graduate Resident, Department of Gynecology \& Obstetrics Unit-II DHQ Hospital, Faisalabad Pakistan \\ 4 Review of literature
}

How to Cite: Ali R, Abid F, Aslam F, Batool S. Comparison of Success Rate of Vaginal Birth after Cesarean Between Women with Lower Segment Uterine Scar Thickness more than and less than 3.5mm. APMC 2021;15(1):17-20. DOI: 10.29054/APMC/2021.1123
CORRESPONDING AUTHOR

Prof. Dr. Robina Ali

Professor, Department of Gynecology, PMC / FMU

Allied \& DHQ Hospitals, Faisalabad Pakistan

Email:dr_rubina_ali@yahoo.com

Submitted for Publication: 22-12-2020 Accepted for Publication 21-02-2021

\section{ABSTRACT}

Background: Although scar thickness is been used for predicting vaginal birth among women with previous one cesarean section but which women are good candidates for VBAC, the value of applying sonographic LUS thickness measurement in the management of VBAC remains unclear and there are no clear guidelines in this regard. Objective: To determine the frequency of successful vaginal birth after previous one cesarean section and to compare the frequency of vaginal birth after previous one cesarean section in women with scar thickness $>3.5 \mathrm{~mm}$ compared to those with scar thickness $\leq 3.5 \mathrm{~mm}$. Study Design: Descriptive, Case-series study. Settings: Department of Obstetrics \& Gynecology, DHQ Hospital, Faisalabad. Duration: Six months from December 15, 2017 to June 15, 2018. Methodology: The Non probability, consecutive sampling technique was used in this study. A total of 151 patients in spontaneous labor at term presented to labor room and fulfilling the inclusion criteria were enrolled in this study. After taking informed written consent, the patients were placed randomly into two groups. Group A included all the women with scar thickness $>3.5 \mathrm{~mm}$ on ultrasonography while Group B included all the women with scar thickness $\leq 3.5 \mathrm{~mm}$ on ultrasonography. All cases were followed till delivery and outcome variables like vaginal birth was noted. Data was entered and analyzed through SPSS version 21. Results: Mean age was $27.53 \pm 4.93$ years. Mean gestational age was $39.09 \pm 1.13$ weeks. Frequency of successful vaginal birth after previous one cesarean section was found in $131(86.75 \%)$ patients, whereas there was no VBAC in $20(13.25 \%)$ patients. The results of the study showed that women with scar thickness $>3.5 \mathrm{~mm}$ were more likely to have vaginal birth $(96.65 \%)$ versus those with scar thickness $\leq 3.5 \mathrm{~mm}(79.27 \%)(\mathrm{P}=0.003)$. Conclusion: This study concluded that the frequency of vaginal birth after previous one cesarean section in women with scar thickness $>3.5 \mathrm{~mm}$ is much higher as compared to those with scar thickness $\leq 3.5 \mathrm{~mm}$.

Keywords: Scar thickness, Vaginal birth after cesarean section, Ultrasonography.

\section{INTRODUCTION}

In first half of $20^{\text {th }}$ century, a caesarean section implied that all subsequent pregnancies were likely to be delivered the same way. The fear behind the idea was rupture of caesarean scar. The notion "one caesarean section, always caesarean section" was found on original procedure of classical caesarean section. ${ }^{1}$ In 1940 lower segment caesarean section replaced the classical one but the fear of catastrophic uterine scar rupture was retained. Later on, nature disclosed the fact that a woman with the previous caesarean section who was scheduled for elective caesarean section went into spontaneous labour and delivered safely. ${ }^{2}$

Caesarean section delivery is the most common surgical obstetric intervention and its rate varies internationally from $10-25 \% .^{3}$ The main indication for caesarean section has become repeat caesarean section. ${ }^{4}$ VBAC avoids major abdominal surgery, lowers a woman's risk of hemorrhage, infection and shortens hospital stay. It also avoids the possible future risks related to having multiple caesareans, such as bowel and bladder injury, transfusion, infection and abnormal placental conditions (placenta previa and placenta accreta). ${ }^{5}$ Naef et al retrospectively reviewed the delivery outcomes of 262 women with lower vertical uterine incisions over a 10year period. Fifty four percent experienced a trial of labor with $83.0 \%$ having a successful vaginal delivery rate. ${ }^{6}$

The rate of attempted vaginal birth after previous cesarean delivery has decreased, but the success rate of such births has increased. This is the result of good 
selection of mothers and adequate quality of ultrasound assessment of uterine scar. ${ }^{7}$

Evaluation of scar thickness is done by ultrasound but it is still debatable scar thickness that would be guiding "cut off" value for the completion of delivery by vaginal method. ${ }^{8}$ Although LUS thickness measured by ultrasound at or near term is being used by $16 \%$ of obstetricians in the world to determine which women are good candidates for VBAC, the value of applying sonographic LUS thickness measurement in the management of VBAC remains unclear and there are no clear guidelines in this regard. ${ }^{9}$ A study was done by Lakhani MS et al ${ }^{10}$ among 108 women with previous one cesarean section. Ultrasound evaluation of the scar was done and frequency of vaginal birth was noted. The results of the study showed that women with scar thickness $>3.5 \mathrm{~mm}$ were more likely to have vaginal birth $(90.57 \%)$ versus those with scar thickness $\leq 3.5 \mathrm{~mm}(0.0 \%)$ $(\mathrm{P}<0.05)$. So, the rationale of my study was to determine the frequency of vaginal birth after cesarean section in women with scar thickness $>3.5 \mathrm{~mm}$ compared to those with scar thickness $\leq 3.5 \mathrm{~mm}$. This had not been studied in local population before.

\section{METHODOLOGY}

Study Design: Descriptive, case series study.

Settings: Department of Obstetrics \& Gynecology, DHQ Hospital, Faisalabad Pakistan.

Duration: Six months from December 15, 2017 to June 15, 2018.

Sample Technique: Non-probability, consecutive sampling.

Sample Size: The calculated sample size was 151 with 95\% confidence level, 6\% margin of error and taking expected percentage of vaginal birth after previous one cesarean section as $83.0 \%{ }^{6}$

Inclusion Criteria: All women with previous one cesarean section with spontaneous onset of labour, gestational age 37-41 weeks (assessed on LMP), patients between 16-35 years of age and singleton pregnancy with cephalic presentation on ultrasonography were included. Exclusion Criteria: Multiple pregnancies, patients with history of ruptured uterus, hysterotomy and classical cesarean section, fetal malpresentation on ultrasonography, patients with more than one cesarean section, patients with vaginal delivery after cesarean section, patients with placenta previa on ultrasonography and patients with cephalopelvic disproportion on clinical pelvimetry were excluded.

Data Collection Procedure: After permission from ethical review committee, a total number of 151 pregnant females who were presented to the Department of Obstetrics \& Gynecology, DHQ Hospital, Faisalabad, fulfilling the inclusion criteria was selected. After taking informed written consent, patients were divided into in to two groups i.e. A and B. Group A included all the women with scar thickness >

$3.5 \mathrm{~mm}$ on ultrasonography while Group B included all the women with scar thickness $\leq 3.5 \mathrm{~mm}$ on ultrasonography. All cases were followed till delivery and outcome variables like vaginal birth was noted by the researcher herself. All this data was recorded on a specially designed Performa (Annexure-I).

Data Analysis: Statistical analysis was performed using SPSS version 21. Results were presented as mean and standard deviation for quantitative variables i.e., gestational age, frequency \& percentage were calculated for qualitative variables like diabetes mellitus, hypertension, obesity, vaginal birth (yes/no), scar thickness ( $>3.5 \mathrm{~mm}$ and $\leq 3.5 \mathrm{~mm}$ ). Vaginal birth was compared by using stratification chi square test for scar thickness ( $>3.5 \mathrm{~mm}$ and $\leq 3.5 \mathrm{~mm})$ and

$p$-value $\leq 0.05$ was considered as significant.

Effect modifiers like age, gestational age, diabetes mellitus, hypertension and obesity were controlled through stratification. Post-stratification chi square was applied to see their effects on outcome and $p$-value $\leq 0.05$ was considered as significant.

\section{RESULTS}

Age range in this study was from 16 to 35 years with mean age of $27.53 \pm 4.93$ years. Majority of the patients $103(68.21 \%)$ were between 26 to 35 years of age as shown in Table 1.

Table 1: Age distribution of patients $(n=151)$

\begin{tabular}{|c|c|c|}
\hline Age (in years) & Number of Patients & Percentage \\
\hline $\mathbf{1 6 - 2 5}$ & 48 & $31.79 \%$ \\
\hline $\mathbf{2 6 - 3 5}$ & 103 & $68.21 \%$ \\
\hline Total & 151 & $100.0 \%$ \\
\hline
\end{tabular}

Mean $\pm \mathrm{SD}=27.53 \pm 4.93$ years

Mean gestational age was $39.09 \pm 1.13$ weeks (Table 2 ).

Table 2: Distribution of patients according to gestational age $(n=151)$

\begin{tabular}{|c|c|c|}
\hline Gestational age (weeks) & Number of Patients & Percentage \\
\hline 37-39 weeks & 100 & $66.23 \%$ \\
\hline $\mathbf{4 0 - 4 1}$ weeks & 51 & $33.77 \%$ \\
\hline Total & 151 & $100.0 \%$ \\
\hline
\end{tabular}

Mean $\pm \mathrm{SD}=39.09 \pm 1.13$ years

Distribution of patients according to hypertension, diabetes mellitus and obesity is shown in figure 1, 2 and 3 respectively. 
Figure 1: Distribution of patients according to hypertension $(\mathrm{n}=151)$

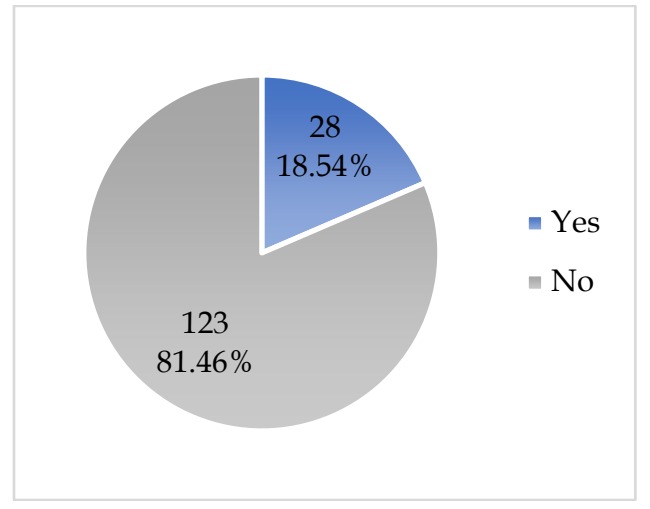

Figure 2: Distribution of patients according to diabetes mellitus $(\mathrm{n}=151)$

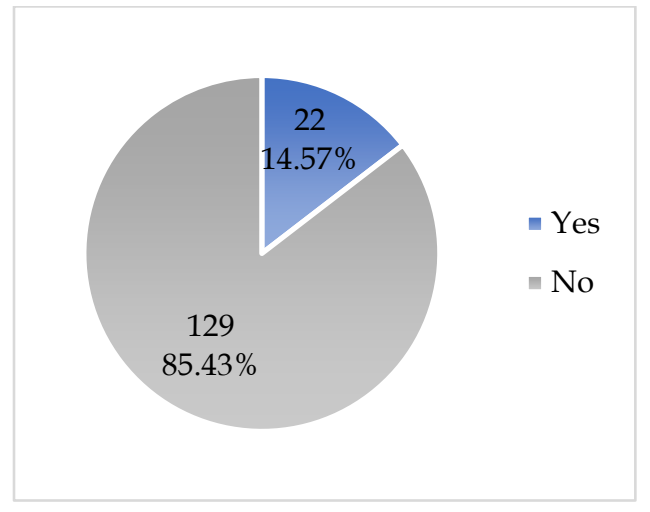

Figure 3: Distribution of patients according to obesity $(n=151)$

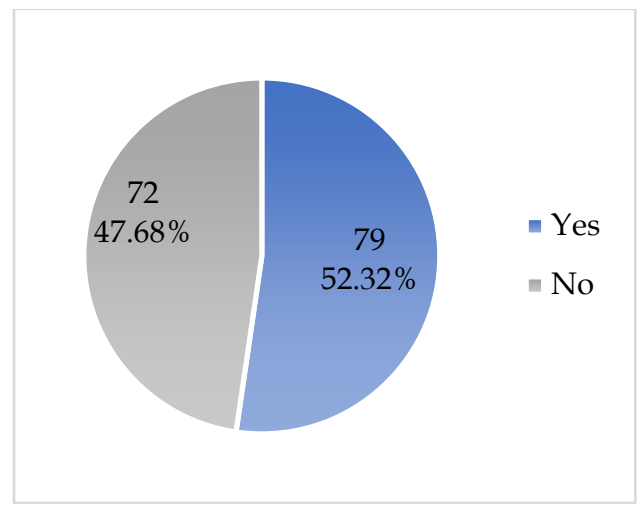

Distribution of patients according to scar thickness is shown in table 3.

Table 3: Distribution of patients according to scar thickness $(\mathrm{n}=151)$

\begin{tabular}{|c|c|c|}
\hline Scar thickness (in mm) & Number of Patients & Percentage \\
\hline $\mathbf{S 3 . 5}$ & 82 & $54.30 \%$ \\
\hline$>\mathbf{3 . 5}$ & 69 & $45.70 \%$ \\
\hline Total & 151 & $100.0 \%$ \\
\hline
\end{tabular}

Frequency of successful vaginal birth after previous one cesarean section was found in 131 (86.75\%) patients, whereas there was no VBAC in $20(13.25 \%)$ patients as shown in figure 4.

Figure 4: Frequency of successful vaginal birth after previous one cesarean section $(n=151)$

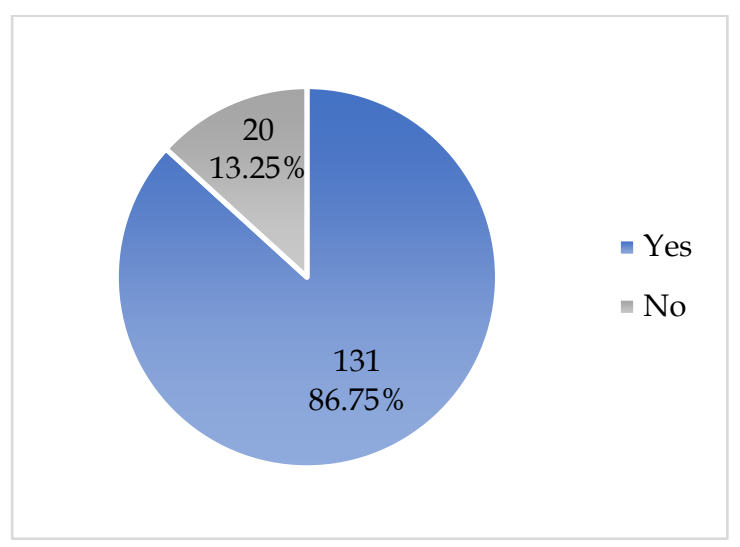

The results of the study showed that women with scar thickness $>3.5 \mathrm{~mm}$ were more likely to have vaginal birth $(96.65 \%)$ versus those with scar thickness $\leq 3.5 \mathrm{~mm}$ $(79.27 \%)(\mathrm{P}=0.003)$ as shown in table 4 .

Table 4: Stratification of VBAC with respect to scar thickness

\begin{tabular}{|c|c|c|c|}
\hline \multirow{2}{*}{ Scar thickness (mm) } & \multicolumn{2}{|c|}{ VBAC } & \multirow{2}{*}{ p-value } \\
\cline { 2 - 3 } & Yes & No & \\
\hline$\leq 3.5 \mathrm{~mm}$ & $65(79.27 \%)$ & $17(20.73 \%)$ & \multirow{2}{*}{$\mathbf{0 . 0 0 3}$} \\
\hline$>3.5 \mathrm{~mm}$ & $66(95.65 \%)$ & $03(4.35 \%)$ & \\
\hline
\end{tabular}

\section{DISCUSSION}

Cesarean section is the most commonly performed surgery in obstetrics. Repeat cesarean section accounts for one third of all cesarean deliveries. Therefore, reduction in the rate of repeat cesarean section will lead to decrease in cesarean section rate. Hence, the importance of more patients being allowed to attempt vaginal birth after cesarean (VBAC) is explained. There is no consensus regarding decision of mode of delivery in patients with previous cesarean section. Despite the known factors which affect the outcome of VBAC like interval between previous cesarean and current pregnancy, indication of previous cesarean section, previous successful vaginal deliveries, postoperative wound sepsis, etc., there are no standard guidelines for patients of previous cesarean section to attempt VBAC. ${ }^{11}$ There is insufficient evidence to recommend the mode of delivery in pregnancies with previous cesarean and this subject continues to be a matter of debate at present.

I have conducted this study to determine the frequency of vaginal birth after previous one cesarean section and to compare the frequency of vaginal birth after previous one 
cesarean section in women with scar thickness $>3.5 \mathrm{~mm}$ compared to those with scar thickness $\leq 3.5 \mathrm{~mm}$. Age range in this study was from 16 to 35 years with mean age of $27.53 \pm 4.93$ years. Majority of the patients $103(68.21 \%)$ were between 26 to 35 years of age. In my study, frequency of successful vaginal birth after previous one cesarean section was found in $131(86.75 \%)$ patients, whereas there was no VBAC in $20(13.25 \%)$ patients. The results of the study showed that women with scar thickness $>3.5 \mathrm{~mm}$ were more likely to have vaginal birth $(96.65 \%)$ versus those with scar thickness $\leq 3.5 \mathrm{~mm}$ $(79.27 \%)(\mathrm{P}=0.003)$. Naef et al retrospectively reviewed the delivery outcomes of 262 women with lower vertical uterine incisions over a 10-year period. Fifty four percent experienced a trial of labor with $83.0 \%$ having a successful vaginal delivery rate. ${ }^{6}$ A study was done by Lakhani MS et al ${ }^{10}$ among 108 women with previous one cesarean section. Ultrasound evaluation of the scar was done and frequency of vaginal birth was noted. The results of the study showed that women with scar thickness $>3.5 \mathrm{~mm}$ were more likely to have vaginal birth $(90.57 \%)$ versus those with scar thickness $\leq 3.5 \mathrm{~mm}(0.0 \%)(\mathrm{P}<0.05)$.

In another study by Rozenberg et al, ${ }^{12}$ it was seen that the risk of uterine dehiscence was directly related to the thinning of lower uterine segment measured sonographically at 37 weeks of gestation. It was advocated in this study that trial of labor can be allowed if the scar thickness at 37 weeks is more than $3.5 \mathrm{~mm}$. Mankuta and colleagues ${ }^{13}$ reported attempted vaginal birth after cesarean section in 50\%, Lyndon-Roche and associates in $60 \%{ }^{14}$ Haller and associates in $83.5 \%$ of cases.

\section{CONCLUSION}

This study concluded that frequency of vaginal birth after previous one cesarean section in women with scar thickness $>3.5 \mathrm{~mm}$ is much higher as compared to those with scar thickness $\leq 3.5 \mathrm{~mm}$.

\section{LIMITATIONS}

This is a small sample size and single center study, no healthy cases has been studied as controls.

\section{SUGGESTIONS / RECOMMENDATIONS}

So, we recommend that scar thickness measurement can help us in recognizing the women with higher chances of vaginal birth after cesarean section and thus in turn reduces the repeat cesarean section in every woman.

\section{CONFLICT OF INTEREST / DISCLOSURE}

No conflict of interest is involved.

\section{ACKNOWLEDGEMENTS}

None.

\section{REFERENCES}

1. Islam A, Ehsan A, Arif S, Murtaza J, Hanif A. Evaluating trial of scar in patients with a history of caesarean section. N Am J Med Sci. 2011;3(4):201-5.

2. Manzoor T, Ambreen A, Anwar K, Ayub R, Mushtaq R. Normal vaginal delivery after one lower segment caesarean section can be safe option for many women but not right choice for all. Ann King Edward Med Uni. 2011;17(1):55-60.

3. Stock SJ, Ferguson E, Duffy A, Ford I, Chalmers J. Outcomes of induction of labour in women with previous caesarean delivery: a retrospective cohort study using a population database. PLoS One. 2013;8(4):e60404.

4. Hill JB, Ammons A, Chauhan SP. Vaginal birth after cesarean delivery: comparison of ACOG practice bulletin with other national guidelines. Clin Obstet Gynecol. 2012 Dec;55(4):969-77.

5. Crowther CA, Dodd JM, Hiller JE, Haslam RR, Robinson JS. Planned vaginal birth or elective repeat caesarean: patient preference restricted, cohort with nested randomized trial. PLoS Med. 2012;9(3):e1001192.

6. Naef RW 3rd1, Ray MA, Chauhan SP. Trial of labor after cesarean delivery with a lower segment, vertical uterine incision - is it safe? Am J Obstet Gynecol. 1995 Jun;172(6):1666-74.

7. Manzoor T, Ambreen A, Anwar K, Ayub R, Mushtaq R. Normal vaginal delivery after one lower segment caesarean section can be safe option for many women but not right choice for all. Ann King Edward Med Uni. 2011;17(1):55-60.

8. Maged AM, Gebril AH, Abdelhafez A. 2D and 3D ultrasound assessment of cesarean section scars and its correlation to intraoperative findings. Uterus Ovary. 2015;2:e919.

9. Cheung VY, Yang F, Leung KY. 2D versus 3D transabdominal sonography for the measurement of lower uterine segment thickness in women with previous cesarean delivery. Int J Gynaecol Obstet. 2011;114:234-37.

10. Basic E, Basic-Cetkovic V, Kozaric H, Rama A. Ultrasound evaluation of uterine scar after cesarean section. Acta Inform Med. 2012;20(3):149-53.

11. Lieberman E. Risk factors for uterine rupture during a trial of labor after cesarean. Clinical Obstet Gynecol. 2001 Sep;44(3):609.

12. Rozenberg P, Goffinet F, Phillippe HJ. Ultrasonographic measurement of lower uterine segment to assess risk of defects of scarred uterus. Lancet. $1996 ; 347: 281$.

13. Mankuta DD1, Leshno MM, Menasche MM, Brezis MM. Vaginal birth after cesarean section: trial of labor or repeat cesarean section? A decision analysis. Am J Obstet Gynecol. 2003;189:174-179.

14. Lydon-Rochelle M, Holt VL, Easterling TR, Martin DP. Risk of uterine rupture during labor among women with a prior cesarean delivery. N Engl J Med. 2001;345:3-8. 